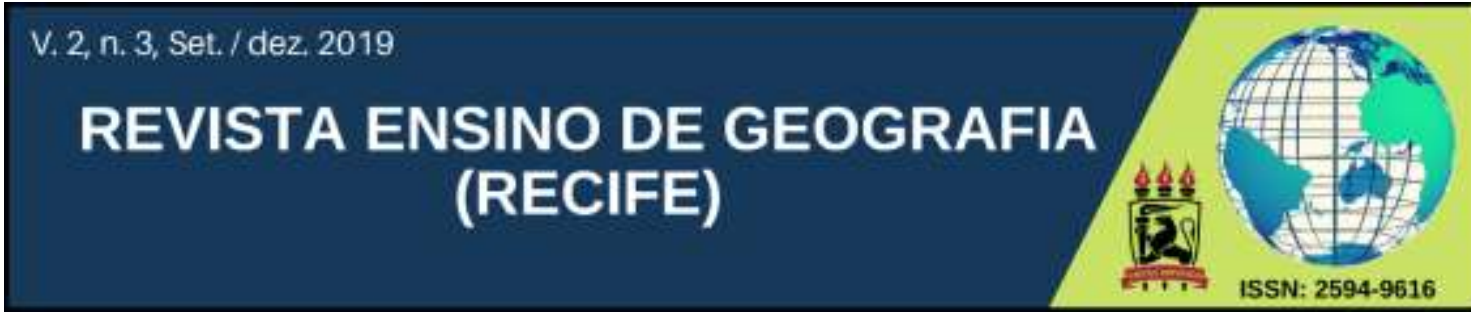

\title{
ENSINO DE GEOGRAFIA: CATEGORIAS DE ANÁLISE E PERCEPÇÕES DO ESPAÇO DE VIVÊNCIA PELOS ALUNOS
}

\author{
Jonas Marques Penha \\ Mestrando em Educação Profissional e Tecnológica - IFPB \\ jonaspenhamarques@gmail.com \\ ORCID Id: http://orcid.org/0000-0002-8523-9517 \\ Josandra Araújo Barreto de Melo \\ Professora do Departamento de Geografia da Universidade Estadual da Paraíba - UEPB \\ ajosandra@yahoo.com.br \\ ORCID Id: https://orcid.org/0000-0002-8523-9517
}

Artigo recebido em 22/08/2019 e aceito em 22/01/2019

\begin{abstract}
RESUMO: Este artigo analisa os resultados das experiências vividas no Estágio Supervisionado do Curso de Graduação em Geografia da Universidade Estadual da Paraíba. As práticas foram desenvolvidas com alunos da turma do $8^{\circ}$ ano "B", na modalidade Educação de Jovens e Adultos - EJA em uma escola da rede estadual da cidade de Campina Grande - PB. O questionamento que orienta esta pesquisa gira em torno de como trabalhar, na geografia escolar, os conceitos e categorias geográficas discutidos na academia. Assim, buscamos, por meio de uma intervenção em sala de aula, possibilitar a aproximação de categorias de análise geográfica ao conhecimento empírico dos alunos. Nessa perspectiva, observamos a dinâmica das aulas do professor regente e o perfil dos alunos para elaborar e aplicar o plano de intervenção. A pesquisa é classificada como descritiva, colaborativa e qualitativamente analisada. As ações ocorreram contextualizando as percepções dos alunos sobre o espaço vivido com conceitos geográficos na construção de um olhar espacial crítico.
\end{abstract}

Palavras-chave: Geografia escolar; Estágio supervisionado; Espaço vivido; Categorias Geográficas.

\section{GEOGRAPHY TEACHING: CATEGORIES OF ANALYSIS AND PERCEPTIONS OF THE SPACE OF EXPERIENCE BY STUDENTS}

\begin{abstract}
This article analyzes the results of the experiences experienced in the Supervised Internship of the Undergraduate Course in Geography of the State University of Paraíba. The practices were developed with students from the class of the 8th year "B", in the modality Education of Young and Adult - EJA in a school of the state network of the city of Campina Grande - PB. The questioning that guides this research revolves around how to work, in school geography, the concepts and geographical categories discussed in the academy. Thus, we seek, through an intervention in the classroom, to enable the approximation of categories of geographic analysis to the empirical knowledge of the students. From this perspective, we observed the dynamics of the classes of the regent teacher and the profile of the students to elaborate and apply the intervention plan. The research is classified as descriptive, collaborative and qualitatively analyzed. The actions occurred contextualizing the students' perceptions about the space lived with geographical concepts in the construction of a critical spatial look.
\end{abstract}

Keywords: School geography; Supervised internship; Space Lived; Geographical categories. 


\section{INTRODUÇÃO}

Conforme análise realizada por Albuquerque (2011), a Geografia, por causas diversas, tem dificuldades em difundir no âmbito escolar as categorias e teorias discutidas no espaço acadêmico, uma distância entre teoria e prática, entre geografia escolar e geografia acadêmica. No entanto, a indissocialidade possibilitaria novos olhares sobre a dinâmica dessa importante ciência e disciplina escolar.

Assim, na formação inicial, os professores sentem-se desafiados a superar a visão do estágio supervisionado apenas como um componente curricular obrigatório, já que ele faz-se imprescindível na formação pedagógica, na aproximação com o cotidiano escolar, possibilitando articular teoria e prática no processo de formação do profissional da Geografia, a partir dos projetos de intervenção desenvolvidos no exercício das regências e pesquisas no espaço escolar. Dessa forma, os licenciandos procuram, com o apoio do(a) professor(a)orientador(a), contribuir com novas abordagens, ressignificar metodologias tidas como tradicionais, procurando dinamizar as aulas e construir relações de ensino-aprendizagem.

Em meio a esse contexto, o presente artigo tem como objetivo analisar os resultados das experiências vivenciadas no Estágio Supervisionado, componente da matriz curricular do curso de Licenciatura em Geografia, da Universidade Estadual da Paraíba - UEPB, desenvolvido na turma do $8^{\circ}$ ano, modalidade Educação de Jovens e Adultos - EJA, de uma escola da cidade de Campina Grande - Paraíba.

O trabalho desenvolvido na escola campo de estágio, mediante projeto de intervenção didático-pedagógica, intencionou resgatar a aplicabilidade das categorias de análises geográficas (Espaço, Território, Região, Paisagem e Lugar), nas aulas de Geografia, haja vista que tais categorias constituem as grandes pilastras da Geografia enquanto ciência e disciplina escolar, o que vem sendo negligenciado na escola, conforme foi possível verificar mediante a observação inicial nas aulas desse componente curricular.

Para tanto, observou-se o espaço escolar, a fim de conhecer melhor sua dinâmica em múltiplas dimensões, a metodologia da professora regente e o perfil da turma, objeto de observação, e intervenção no estágio supervisionado. A partir disso, foi elaborado um projeto no qual se propõe analisar a importância do resgate das categorias de análise geográficas, possibilitando a articulação entre as diferentes escalas geográficas, sempre tendo como âncoras as categorias de análise geográficas, especialmente o lugar, no Ensino Fundamental, 
modalidade EJA, para assegurar o estudo da espacialidade, fundamental para a formação do indivíduo e afirmação da Geografia na escola.

O trabalho foi desenvolvido na perspectiva da pesquisa colaborativa descritiva e de abordagem qualitativa. O aporte teórico abordou temas e teóricos na esperança de dar suporte aos procedimentos metodológicos e pedagógicos adotados, além de conceitos fundamentais, tais como espaço geográfico, território, região, paisagem e lugar. Destarte, destacamos Callai (2001); Andrade (2004); Cavalcanti (1998; 2005; 2010); Santos (1988); Almeida, (1991); Pontuschka et al (2009); Saiki; Godoi (2010); Ticks (2008) e; outros.

Iniciamos a dissertação desse artigo discutindo a importância do uso das categorias de análises geográficas na EJA, dando ênfase à categoria geográfica lugar. Já as demais categorias são discutidas concomitantemente no andamento da pesquisa, seus resultados e discussões. Com isso, trazemos o processo de desenvolvimento da pesquisa culminado com a intervenção didático-pedagógica. Por fim, tecemos nossas considerações acerca do trabalho e suas contribuições e perspectivas futuras.

O trabalho nos permitiu perceber a evolução na qualidade do aprendizado dos estudantes, quando sua dinâmica cotidiana, seu lugar, é ponto de partida para estudos melhores elaborados dos conceitos.

\section{AS CATEGORIAS DE ANÁLISE GEOGRÁFICAS NO ENSINO FUNDAMENTAL, MODALIDADE EDUCAÇÃO DE JOVENS E ADULTOS - EJA}

A constituição de 1988 amplia o dever do Estado de garantir educação a todos os cidadãos brasileiros, independente da faixa etária, emergindo, com isso, iniciativas voltadas à redução do índice de analfabetismo no País. Considerando que, mesmo lento, tem aumentado a expectativa de vida no Brasil, e o Governo tem investido na Educação de Jovens e Adultos EJA, seja para cumprir exigências internacionais, seja para melhorar a qualidade de vida da população.

Segundo Soares (2001, p. 205):

Em lugar de reduzir o processo educativo à mera preparação para o mundo do trabalho, podemos avançar em direção a uma concepção mais ampla, que considere as demais dimensões da educação: a emergência e o fortalecimento do sujeito situase como o objetivo prioritário da prática educativa.

Nesse contexto, o ensino de Geografia pode contribuir tanto com o processo de alienação dos indivíduos, mediante práticas desconectadas com a realidade dos alunos, quanto 
desempenhando um papel revolucionário, a partir do repensar contínuo do espaço vivido, o que vem a calhar com o despertar do aluno para a criticidade acerca dos objetos e ações do espaço geográfico. Nesse sentido, “o conhecimento geográfico é, pois, indispensável à formação de indivíduos participantes da vida social, à medida que propicia o entendimento do espaço geográfico e do papel desse espaço nas práticas sociais” (CAVALCANTI, 1998, p. 11). Com isso, a geografia escolar pode e deve ser voltada para contribuir na formação de sujeitos capazes de desenvolver o pensamento crítico e autônomo sobre seus lugares.

Na ótica de Diniz; Compiani (2017, p. 68);

Como sugestão às dificuldades encontradas no ensino de geografia, vemos a construção de conhecimento escolar baseada na contextualização como uma delas. Isto é, privilegiando os estudos locais, como por exemplo, os problemas encontrados na sala de aula, no entorno da escola, no bairro, na cidade.

Assim, vemos, como possibilidades, propostas de mediações pedagógicas no ensino de geografia que sejam ancoradas na contextualização dos conteúdos sistematizados com os da vivência do alunado, com lugar. Desse modo, a relação professor-aluno dever ser harmônica e fundamental, no processo de construção de conhecimentos, tornando a Geografia mais interessante, partindo dos conhecimentos prévios dos alunos em consonância com conteúdos mais próximos da realidade deles, da dinâmica cotidiana dos envolvidos, elevando-os às escalas mais abrangentes dos fenômenos.

[...] um trabalho pedagógico que vise à ampliação das capacidades dos alunos do ensino fundamental de observar, conhecer, explicar, comparar e representar as características do lugar em que vivem e de diferentes paisagens e espaços geográficos (BRASIL, 1998, p. 15).

Esses aspectos podem ser relacionados a uma Geografia a serviço do ser humano, preocupada não apenas com o material, mas com ênfase na experiência vivida pelos sujeitos nos espaços buscando compreender a totalidade a partir das relações dos espaços que estão próximos, do que está ao alcance dos olhos, das paisagens.

Nessa perspectiva, será que os professores que atuam com a Geografia Escolar têm assumido posturas de profissionais mediadores na construção do conhecimento geográfico? Esses, têm utilizado as teorias, categorias, conceitos geográficos no intuito de contribuir com a formação de indivíduos para a vida?

Segundo Lana de Souza Cavalcanti:

Entre o homem e o lugar existe uma dialética, um constante movimento: se o espaço contribui para formação do ser humano, este, por sua vez, com sua interação, com 
seus gestos, com seu trabalho, com suas atividades, transforma constantemente o espaço (CAVALCANTI, 1998, p.24).

As categorias de análise geográficas constituem os pilares de sustentação da Geografia enquanto ciência, elas representam os diversos olhares sobre o espaço, pois a dimensão social se constitui no cerne das dinâmicas dos territórios, das regiões, das paisagens, dos lugares, etc. "O mundo encontra-se organizado em subespaços, articulados dentro de uma lógica global" (SANTOS, 1988, p.17). As discussões conceituais acerca das categorias de análise geográficas agregadas aos conteúdos e às percepções do cotidiano dos alunos repercutem positivamente, tanto na formação dos indivíduos, tornando-os conhecedores de si e da dinâmica espacial, quanto no fortalecimento científico da Geografia, na escola.

Destarte, é importante ressalvar que, quanto mais cedo apresentar as categorias geográficas aos indivíduos, mais suas relações com essas serão ativas e conscientes. Para Cavalcanti (2005, p. 187), “[...] o pensamento, o desenvolvimento mental, a capacidade de conhecer o mundo e de nele atuar é uma construção social que depende das relações que o homem estabelece com o meio". Assim, é perfeitamente possível trabalhar a partir dessa perspectiva, das percepções do espaço vivido, junto a um público de jovens e adultos, usando suas experiências como ponto de partida para construção do conhecimento.

Para Callai (2001, p. 136);

O professor deverá propor o estudo que seja conseqüente para os alunos. E as experiências concretas deverão ter interligamento e coerência dentro do que é ensinado, pois o vivido pelo aluno é expresso no espaço cotidiano, e a interligação deste com as demais instâncias é fundamental para aprendizagem.

Tais experiências socioespaciais, muitas vezes empíricas, podem e devem ser valorizadas na sala de aula, intermediadas pelo professor(a), através das discussões acerca desses conhecimentos, construindo um elo entre as percepções cotidianas e o conhecimento científico sistematizado do currículo escolar, contribuindo para a formação desses indivíduos, fazendo a ciência desempenhar o seu papel social. Segundo Almeida (1991, p. 89), "os professores precisam perceber que seu papel no processo de democratização de nossa sociedade consiste em, principalmente, desenvolver uma prática pedagógica não alienante, mas conscientizadora".

O professor(a) de Geografia deve se empenhar no ensino de uma Geografia questionadora e esclarecedora, capaz de libertar o indivíduo para a vida e galgar no sentido da democratização da sociedade. Para Cavalcanti (2010, p. 141), “devem-se levar em conta o lugar e a realidade cotidiana do aluno, com o pressuposto de que torna mais significativo e o aluno 
mais interessado pelas atividades escolares". A formação para a vida requer posicionamento crítico sobre os fenômenos, especialmente os que ocorrem na dinâmica cotidiana.

\section{A EXPERIÊNCIA NO ESPAÇO ESCOLAR: INTERVENÇÃO DIDÁTICO- PEDAGÓGICA EM SALA DE AULA}

O estágio supervisionado, observações e intervenções didático-pedagógica ocorreram na turma do $8^{\circ}$ ano "B", modalidade Educação de Jovens e Adultos - EJA, da escola Senador Argemiro de Figueiredo (Polivalente), da rede estadual de ensino da cidade de Campina Grande-PB, localizada no bairro Catolé, zona sul. Segue figura 1, destacando sua localização.

Figura 1: Localização da Escola Senador Argemiro de Figueiredo (Polivalente).

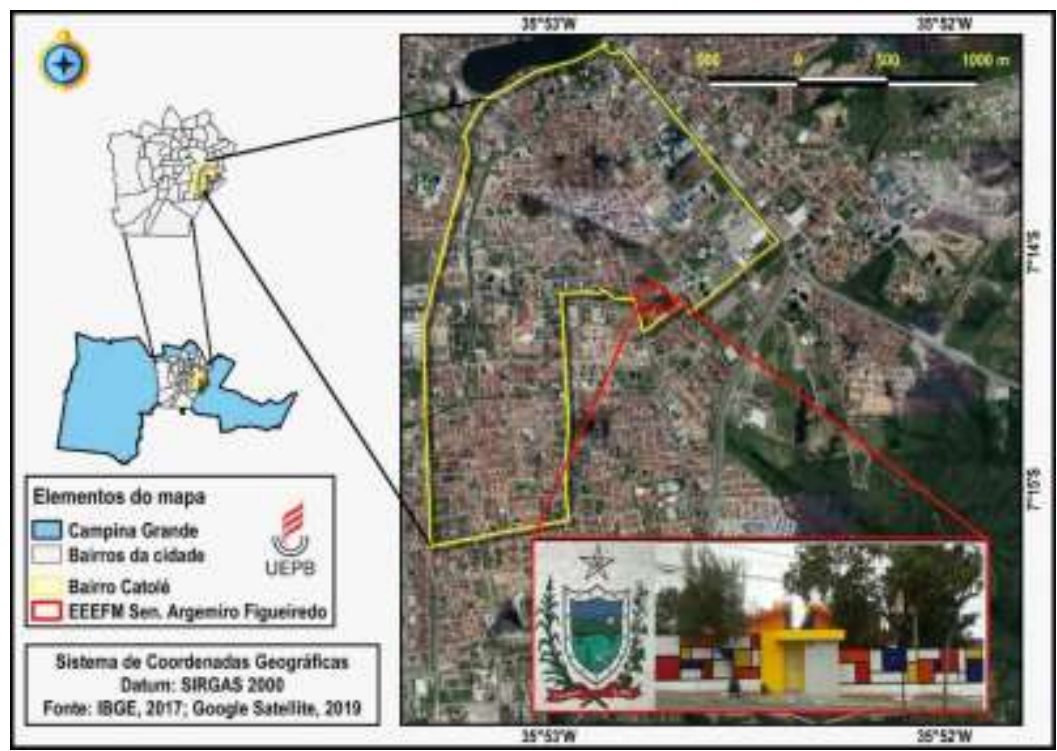

Fonte: Elaboração de Janaina da Silva Santos (2019).

Adentrando ao espaço escolar e presenciando as aulas ministradas pela professora regente, foi possível identificar pontos importantes que são passíveis de serem investidos no processo de ensino-aprendizagem, especialmente de forma colaborativa. No componente curricular Estágio Supervisionado, a interação predominou entre estagiário, professora supervisora de estágio, professora regente e a turma do $8^{\circ}$ ano "B", EJA. Assim, foi possível elaborar uma estratégia de intervenção, de forma a assegurar o envolvimento da turma objeto de estudo-intervenção.

O caráter colaborativo dessa pesquisa justifica-se à medida que, desde o processo de observação in loco, em sala de aula, até a intervenção na turma, houve o envolvimento direto e intencional dos colaboradores, tanto nos planejamentos e logística, quanto nas orientações teórico-metodológicas e didáticas.

\begin{tabular}{lll}
\hline Penha e Melo, 2019 & ISSN 2594-9616
\end{tabular}


Concordando com Franco (2009, p. 48), numa pesquisa colaborativa;

[...] requer cuidado na coleta de dados, na análise, nas considerações das dúvidas metódicas; esse trabalho metodológico-reflexivo é que vai indicar a possibilidade de novas hipóteses que vão sendo levadas aos práticos e que podem referendar novas ações.

A docência, em Geografia, requer um exercício diário de observação e de leituras do presente imediato, da dinâmica, frutos das múltiplas relações entre pessoas de diferentes contextos, mas que convergem no espaço escolar, na sala de aula, em torno de objetivos semelhantes - a busca pelo conhecimento. Nesse contexto, segundo Ticks (2008, p. 2); "a pesquisa colaborativa procura não apenas descrever e explicar as ações vivenciadas pelos participantes no contexto de sala de aula, mas também, interferir em sua prática pedagógica, possibilitando sua reconfiguração de modo reflexivo e colaborativo". Ressaltamos, fundamentados em Pontuschka et al (2009), a importância da pesquisa enquanto atitude cotidiana na construção de conhecimentos significativos, de interpretação da realidade, de autonomia discente.

A carga horária de atuação do estagiário, na escola, é insuficiente para fazer uma leitura condizente com a realidade desse espaço. Existem diversas etapas e relações que acabam por não serem vivenciadas durante o estágio, devido ao curto período de contato direto. "Num Curso de Licenciatura seria desejável uma maior valorização da disciplina Prática de Ensino, não se limitando a alguns meses de estágio em sala de aula" (SAIKI; GODOI, 2010, p. 29). Muitas vezes, não há tempo suficiente sequer para traçar o perfil da turma objeto da intervenção e nem tempo para fechar o ciclo sistêmico de ensino, que se inicia com o planejamento, introdução e discussão dos conteúdos, culminando com a avaliação, reforço e recuperação para, assim, conduzir, mediante o crescimento intelectual do aluno, à série seguinte.

Como alhures mencionado, é sabido que o tempo de estágio não é o ideal, e isso acontece por motivos diversos, deve-se explorar o máximo da estadia no espaço escolar, envolver-se, entregar-se e estar aberto para melhor absorver as avalanches de informações e choques culturais existentes. "Conhecer a organização do espaço escolar e as relações entre os sujeitos é uma necessidade, na medida em que a aula não é um acontecimento isolado de uma sala, mas está inserida no espaço social de uma instituição de ensino" (SATO; FORNEL, 2010, p. 53). Portanto, trata-se de um laboratório de análise contínuo cujos resultados, mesmo repetindo minuciosamente os mesmos métodos e didática, sempre serão diferentes.

Intervenções: elo entre categorias geográficas, conteúdos e experiências dos alunos 
Conscientes de que se tratava de um estágio de período de observação e regência relativamente curto foi proposto e desenvolvido um projeto de intervenção pautado na realidade da turma e no tempo de vigência do componente curricular sempre preocupados em não comprometer a sequência dos conteúdos planejados pela professora regente.

Dessa forma, a regência ocorreu levando-se em conta as propostas elencadas pelos Parâmetros Curriculares Nacionais de Geografia, mais especificamente do $1^{\circ}$ e $2^{\circ}$ eixos temáticos do Quarto Ciclo, na perspectiva de abordar as discussões conceituais das categorias geográficas, em conjunto com a gama de conhecimentos trazidos pelos alunos, a partir do contato com o espaço e a troca de experiências vivenciadas.

O trabalho desenvolvido na turma da EJA, $8^{\circ}$ ano do ensino fundamental, teve como efetivo período de intervenção direta, pós-observações e planejamentos, o período de quatro encontros de 2 horas/aulas cada. Iniciou-se com a abordagem da categoria lugar representada pelo espaço vivido, que é a categoria mais próxima do indivíduo, de onde emergem o mundo dos significados, dos conhecimentos cognitivos. Segundo Bock et al. (2002), os conhecimentos cognitivos têm origem a partir das primeiras relações de significado entre o ser e o mundo, que são os pontos de partida para a atribuição de outros significados.

Nas discussões acerca do lugar, a partir da concepção dos alunos e do conceito científico, eles se sentiram à vontade para se expressarem. Descreveram cada detalhe de seus lugares. Empiricamente, tal subespaço já está imbuído no íntimo dos indivíduos, no entanto banalizado, sem muita atenção. "O lugar se refere de forma indissociável ao vivido, ao plano do imediato. E é o que pode ser apropriado pelo corpo [...]" (CARLOS, 2007, p.19). Constatamos, nos textos dissertados dos estudantes, que eles(as) têm seus próprios conceitos definidos e percebidos na vida social.

Em atividade mediada em sala de aula, quando os alunos formam questionados sobre seus lugares obtivemos as seguintes respostas. Destacadas nas imagens a seguir: 
Figura 1: Respostas, respectivamente, dos alunos " $A$ ", "B" e "C" quanto ao lugar.

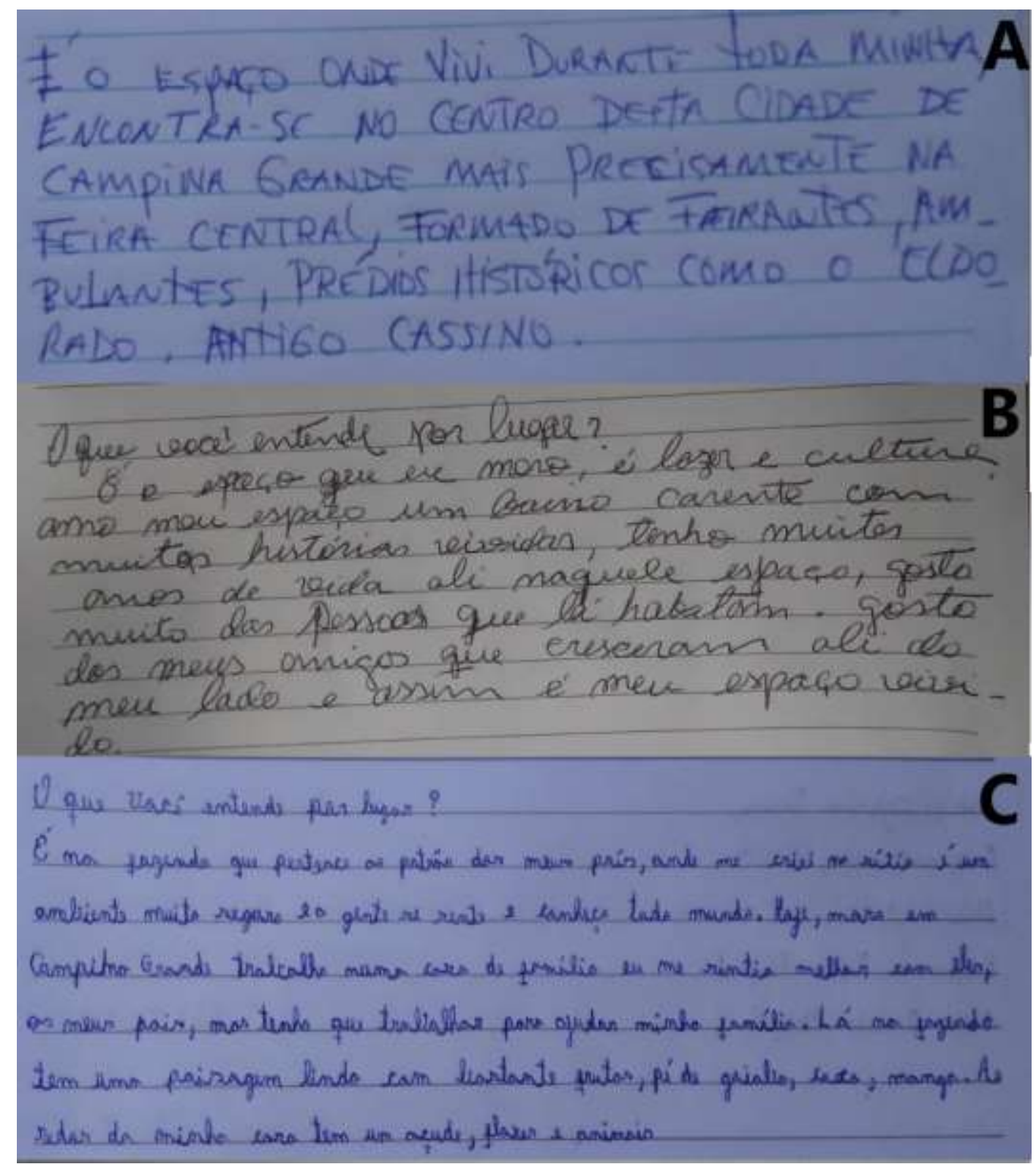

Fonte: Acervo pessoal dos autores (2018).

Percebe-se, nos discursos dos estudantes, que eles se reconhecem nas paisagens, nos elementos que compõe e dão sentido ao espaço de interação direta no cotidiana. Assim, entender o lugar é entender a si próprio, visto que espaço e ser humano formam uma unidade. "[...] os lugares são partes do todo, é onde se dão as histórias de todas as ações e onde se estabelecem nossas relações, ligações e sentido de pertencimento" (DINIZ; COMPIANI, 2017, p. 68). Pôdese facilmente constatar relações socioespaciais de identificação do aluno com as paisagens por eles citadas, com a descrição dos seus lugares.

Desta forma, a configuração de espaço enquanto lugar está ligado diretamente às relações de intimidade entre ser humano e paisagem, a sensação de pertencimento. "O lugar [é] 
o ponto de práticas sociais específicas que nos moldam e nos formam e com as quais nossas identidades estão estreitamente ligadas" (HALL, 2006, p. 72), conforme ficou explícito nas produções textuais dos alunos. Essa identificação do indivíduo com o espaço vivido propõe o desenvolvimento da cultura local, visto que em cada lugar as expressões culturais são reflexos das relações socioespaciais existentes.

A relação para com esse espaço de acontecimentos e de construção de conhecimentos empiristas resulta na propagação e valorização das raízes culturais dos indivíduos. Desse modo, inseriram-se nas discussões, durante as intervenções, conteúdos acerca da cultura e diversidade cultural brasileira e das territorialidades.

Isso posto, orientamos a regência tendo em vista a valorização das relações socioespaciais vividas e percebidas pelos alunos, facilitando a compreensão das categorias geográficas e proporcionando condições de ampliar seus conceitos preestabelecidos. Por exemplo, para conceituar a categoria território partiu-se das indagações feitas aos alunos sobre a compreensão que eles tinham do conceito.

No decorrer da aula, em meio às discussões, o aluno "D" fez referência ao "território do tráfico de drogas". Outros indagaram foram feitas acerca do território nacional, quando nos apresentaram como sendo sinônimo de Brasil, de Países. Nesse momento, de forma a avançar para o conceito sistematizado pela ciência geográfica, intensificamos as discussões, inserindo provocações a respeito de determinadas influências, relações de poder, exercidas por um indivíduo ou um grupo sobre determinado espaço. Nesse sentido, os estudantes elencaram diversos exemplos, como espaços residências (casa) e até mesmo compartimentos de seus lares, como quartos, sala, cozinha que, segundo eles, cada membro da família exercer maior ou menor influência, poder, sobre esses espaços.

Assim, paulatinamente, os estudantes foram ampliando os olhares para as escalas mais abrangentes, fundamentando-se no conceito de território discutido em sala. Para Andrade (2004, p. 19), “o conceito de território não deve ser confundido com o de espaço ou de lugar, estando muito ligado à ideia de domínio ou de gestão de determinada área". Dessa forma, retomou-se às ideias iniciais a respeito de território nacional, de espaço submisso a uma gestão e influências, e até mesmo do poder que traficantes exercem sobre determinados espaços.

Ainda sobre território, as discussões transitaram pelo tema movimentos migratórios. Utilizamos como exemplos as experiências de alunos que migraram de outras cidades para Campina Grande, elencando as causas e motivos das migrações, contextualizando com o 
histórico das migrações no mundo, Brasil e Paraíba, abordando as questões de territorialidades, identidade territorial, premissas para definir o espaço enquanto território.

Diante disso, os estudantes puderam considerar que, à medida que as pessoas chegam a um lugar estranho, não se sentem parte desse espaço, passando a se sentirem integrantes a partir das novas relações criadas e cristalizadas em suas identidades. "A formação de um território dá às pessoas que nele habitam a consciência de sua participação, provocando o sentido da territorialidade que, de forma subjetiva, cria uma consciência de confraternização sobre elas" (ANDRADE, 2004, p. 20). As dificuldades de adaptação ao novo espaço induzem à criação de colônias, réplicas da terra natal, a exemplo das colônias japonesas, portugueses, alemãs e outras espalhadas pelo Brasil, assim como bairros habitados por nordestinos, comuns na região Sudeste, como sinal de resistência.

Como é perceptível, ao longo das ações pedagógicas, o lugar foi trabalhado inclusive na compreensão das demais categorias de análises geográficas. "Ao estudar o local, permitimos aos alunos não só constatar, mas inclusive olhar de forma mais complexa a sua organização e valorizá-lo por ser um meio próximo no qual o aluno está inserido, sendo palpável e conhecido" (DINIZ; COMPIANI, 2017, p. 69). Assim, foi trabalhado em sala de aula (áudio e texto) a música "O último Pau de Arara" interpretada por Raimundo Fagner, letra de Venâncio/Corumbá/J. Guimarães, na perspectiva do lugar, das identidades territoriais como forma de resistência a desterritorialização causada pelas migrações, exemplificando com o apego do nordestino pelo sertão, identidade territorial bem representada na letra da música.

Ademais, as discussões propiciaram uma introdução ao trabalho com a categoria região, cujo conceito foi trabalhado com o auxílio de mapas políticos do Brasil, Paraíba e de Campina Grande, por meio de análise das suas peculiaridades, localizando suas especializações, seja nos âmbitos natural, cultural ou econômico, na perspectiva de diferenciação de áreas. Segundo Corrêa (1987, p. 45), “[...] a região pode ser vista como um resultado da lei do desenvolvimento desigual e combinado, caracterizada pela sua inserção na divisão nacional e internacional do trabalho e pela associação de relações de produção distintas”. Diante disso, exploramos o exemplo de um aluno que morou na cidade de Sapé - Paraíba. Segundo aluno D; “[...] a minha cidade é conhecida como região do abacaxi”. Nesta cidade, é comum a produção do abacaxizeiro, portanto Sapé diferencia-se de outras cidades a partir desta cultivar, conhecida por estar inserida na região produtora de abacaxi (Ananas comosus L. Merril). Assim como esse exemplo, outros surgiram na sala de aula que enriqueceram as discussões, como as especificidades de algumas áreas e bairros das cidades. 
Corroborando com Santos (1988, p. 17):

Num estudo regional se deve tentar detalhar sua composição enquanto organização social, política, econômica e cultural, abordando-lhe os fatos concretos, para reconhecer como a área se insere na ordem econômica internacional, levando em conta o preexistente e o novo, para captar o elenco de causas e conseqüências do fenômeno.

Contextualizando o conceito de região às citações voluntárias dos alunos, foi possível introduzir o tema "Cultura e diversidade cultural no Brasil". Discutimos a diversidade cultural na visão de regionalização dos espaços, a partir das expressões culturais e identidades territoriais de seus habitantes. Tomado como exemplo as peculiaridades culturais hábitos e costumes, diferenciadas nas distintas regiões brasileiras.

As peculiaridades regionais, como por exemplo, a língua, a cultura, o clima e outras propiciaram entrar na discussão sobre as diferentes paisagens. A princípio, tal categoria foi descrita pelos alunos como "imagens de lugares bonitos"; "um lugar bonito"; "uma foto"; "um quadro pintado". Partindo desses exemplos, buscou-se trabalhar na perspectiva da desconstrução da ideia de paisagem como algo estático, sem movimento. "Tudo aquilo que nós vemos, o que nossa visão alcança, é a paisagem. Esta pode ser definida como o domínio do visível, aquilo que a vista abarca. Não é formada apenas de volumes, mas também de cores, movimentos, odores, sons, etc.” (SANTOS, 1988, p. 21). Desse ponto de vista, a paisagem representa a sucessão de acontecimentos pretéritos, que resulta na realidade atual. Podendo ser de caráter humano, a construção de uma cidade, desmatamentos e outros, ou naturais, como terremotos, furacões, intemperismos, etc.

Desta forma, com o intuito de aproximar o objeto de estudo à dinâmica do aluno, utilizamos a própria estrutura física e antropogênica da sala de aula como exemplo para contribuir para a conceituação da paisagem. Solicitamos três alunos para vir até a frente da turma e descrever a paisagem visualizada. Cada um fez uma leitura diferente, um observou a desorganização das carteiras; o segundo questionou o pequeno número de alunos em relação ao tamanho da sala; o terceiro, mesmo não levando muito a sério, observou em sua leitura que meninas sentam à frente e os "bagunceiros" atrás.

Na sequência, abrimos uma roda de discussão acerca do apresentado e chegamos à conclusão que a leitura de uma paisagem depende do olhar do observador, do quanto àquela imagem representa para ele, do quanto se sabe sobre ela, do quanto se importa com o que se está vendo. Assim, discutimos a categoria paisagem como representação dos objetos 
circundantes, resultado de sucessivas alterações, imbuídos de sentimentos e significados. A parte física do espaço ganha vida, refletindo as ações dos indivíduos sobre este.

Isso posto, elencamos alguns questionamentos que podem nortear as leituras e análises das paisagens, tais como; O que aconteceu para que essa paisagem chegasse a esse estado? Quais as funções e serviços oferecidos? Quem ocupa esse espaço? O que pode ser feito para melhorar? De quem é a culpa ou o mérito por esse resultado? E outras.

Por fim, no último encontro, as discussões foram acerca da categoria espaço geográfico, por ser a mais complexa e abranger as demais de análises da Geografia, melhor, o objeto de estudo dessa ciência. Dando sequência, foi questionado junto aos alunos o que eles entendiam por espaço. As diversas respostas foram elencadas em colunas na lousa. Obtivemos as seguintes respostas: "é tudo!"; "a sala é um espaço"; "um lugar vazio"; "qualquer canto"; e outras.

Diante dos significados citados pelos alunos, ampliamos o debate direcionando as discussões para "espaço geográfico", conceituando-o segundo Santos (1988, p. 10): "O espaço não é nem uma coisa, nem um sistema de coisas, senão uma realidade relacional: coisas e relações juntas". Diante dessa ideia, podemos afirmar que ser humano é o agente produtor do espaço, e é na escola, a partir do contato com o conhecimento sistematizado, que o indivíduo toma consciência do quanto é produtor e produto desse espaço, que está inserido na sua dinâmica de construção e reconstrução.

Destarte, discutimos sobre o espaço, utilizando a sala de aula como exemplo de espaço geográfico e procurando provocar a turma quanto as suas análises subjetivas, seus objetos e as ações imbuídas.

As principais discussões desse encontro giraram em torno das funções e intenções existentes, de agentes internos e externos a esse espaço, de forma a concluirmos que a relação do ser humano com o espaço resulta no espaço geográfico. Nessa linha de pensamento, trabalhamos de forma ampla conteúdos acerca da diversidade cultural da Paraíba, do Brasil e do mundo, dos movimentos migratórios.

A maximização gradativa na escala de compreensão do espaço, Sala de aula/Campina Grande/Paraíba/Brasil/Planeta, proporcionou ao aluno se enxergar no contexto espacial local e global. Elencaram uma série de ações, hábitos e costumes, relações socioespaciais, quase que comuns globalmente como o consumo de vestuários, jeans; alimentos, pizza, modalidades esportivas, futebol, etc.; e outros mais restritos a determinadas regiões como foi citado, a exemplo de música, de forró; comidas típicas, pamonha, milho assando; e formas de comunicações linguísticas, a exemplo da Região Nordeste e da Paraíba. 
Como vimos, no decorrer das intervenções, em aula, foram desenvolvidas atividades (escritas ou discursivas) como produções textuais, interpretações de músicas e expressões orais, voluntárias e/ou sob provocações. Ambas utilizadas como parâmetros para avaliação do avanço intelectual dos alunos, atribuição de notas, como da eficácia das metodologias de ensino utilizadas e para a elaboração dos planos de aulas subsequentes.

Como coincidiu com o período de provas da instituição, elaboramos tal documento avaliativo corroborando com a linha de pensamento de Vasconcellos (2003), de forma a minimizar as tensões que esse momento provoca, esclarecendo os conteúdos e pesos atribuídos às questões. Primamos por questões discursivas e de correlação de coluna com pretensão de provocar o raciocínio crítico sobre os temas abordados. Como exemplo, elaboramos uma questão que fazia referência às categorias de análise geográficas, e ela propunha que os alunos correlacionassem as colunas. Logo abaixo destacamos, na imagem 2, o fragmento poético que representou o lugar em uma das questões da atividade.

Figura 3: O fragmento poético da música “Alô Palmeira dos Índios".

Não me esqueço dos
Meus amigos
Nem dos forrós que dancei
Não me esqueço
A minha mata
Aquela que lá deixei
A mata me dá saudade
Brevemente voltarei
Pra rever minha cidade
Onde eu nasci e me criei.

Fonte: Composição de Durval Vieira e Joci Batista/Interprete: Jackson do Pandeiro.

Na coluna I, estavam os fragmentos poéticos enumerados de 1-4; e na coluna II, elencadas as categorias: território, região, paisagem e lugar. As respostas dos alunos representaram um avanço quanto à aproximação destes aos conceitos das categorias de analise geográficas. Dos 12 (doze) alunos que fizeram a prova, apenas dois interpretaram os poemas, confundindo o conceito de lugar com o de região, os demais obtiveram 100\% de acerto nessa questão. 
Essa relação entre os conceitos científicos, categorias de análise geográficas e os conteúdos programáticos com os acontecimentos comuns ao convívio dos alunos facilitaram a compreensão e a construção de conceitos geográficos, resultando numa elevação do nível intelectual da turma.

\section{CONSIDERAÇÕES FINAIS}

Os Estágios Supervisionados são componentes curriculares muito importantes para os cursos de licenciaturas, visto que se constituem em um momento de aproximação com o espaço escolar, bem como uma boa oportunidade de explorar este espaço com o olhar da pesquisa, de teorizar a prática, observar o campo de atuação, fazer leituras para possíveis intervenções em prol da construção do conhecimento. Mesmo se tratando de um curto período de tempo, na escola, o estágio pode ser muito bem aproveitado, desde que haja empenho e compromisso dos envolvidos nesse processo. Este deve ser encarado como laboratório. Se não existe fórmula pronta para dar uma boa aula, existem aulas para se propor novas fórmulas.

Observamos que houve mudanças no discurso teórico-acadêmico e no currículo escolar, mas os métodos didático-pedagógicos aplicados não mudaram muito, mostrando existir a reprodução de um modelo tradicional de ensino. No entanto, assim como nesse trabalho, enquanto profissionais da educação, especialmente da geografia, temos que buscar a ressignificação das práticas arcaicas, numa perspectiva de mudanças gradativas de postura profissional, empatia com o outro.

Entendemos que com a Geografia moderna houve um grande passo rumo a uma melhor qualidade no ensino de geografia. No entanto, ainda são muitos os problemas que surgem como entraves, como por exemplo, a qualidade da formação inicial e continuada dos docentes, a desvalorização dos profissionais da educação e o descaso com as estruturas físicas e de pessoal das instituições. Mesmo nessa conjuntura uma coisa que pode possibilitar uma resistência ao sistema é o interesse dos profissionais, a intenção e vontade de transformação social em prol de uma sociedade mais justa e igualitária.

Assim sendo, é preciso que não confundamos professores com "salvadores da pátria" evidente que devemos ter potencial para surpreender, o que não nos coloca no patamar de superheróis, de onipotentes. O que se propõe são mudanças no comportamento profissional, que se desprenda da vaidade do saber tudo; das aulas de outrem; que o livro didático não se transforme num método de aulas monótonas ao invés de um recurso, mesmo que seja o único disponível. 
Na prática, verificamos que é possível desenvolver, mesmo sem recursos sofisticados, um elo entre os conteúdos propostos, os conceitos das categorias de análise geográficas e os conceitos pré-definidos empiricamente pelos alunos, elevando o seu nível do conhecimento, saindo da mera percepção do cotidiano ao melhor elaborado e sistematizado conhecimento científico.

As teorias de ensino de Geografia, por sua vez, vêm ganhando espaço nas publicações e discussões acadêmicas e o dever dos (as) professor (as), por estarem mais próximos dos alunos, é acreditar nas possibilidades de mudanças, investir num ensino capaz de ser uma ferramenta libertadora e formadora de indivíduos que se reconheçam como parte integrante do todo, que tenham o senso crítico aguçado, cidadãos conscientes de suas responsabilidades, cumprindo seus deveres e reivindicando seus direitos, pré-requisitos básicos para o exercício da cidadania.

Quanto à inserção conceitual das categorias geográficas, não se pode afirmar que essa intervenção, resumida nesse artigo, tenha sido suficiente para que os alunos detenham o domínio integral sobre tais conceitos, mas, certamente, não serão conceitos vistos como temáticas estranhas, o que facilitará o entendimento nas futuras aulas. Entendemos que houve um significativo crescimento intelectual por parte da turma acerca dos conceitos trabalhados, categorias de analises geográficas, passaram a associar suas percepções, adquiridas cotidianamente no espaço de vivência, com os conceitos geográficos apresentados, compreendendo, assim, suas participações na construção e reconstrução espacial.

A significância e proximidade dos conteúdos discutidos em sala de aula com a dinâmica diária dos alunos foram os grandes elos para as relações professores (estagiário) e alunado rumo à construção do conhecimento. Podemos afirmar que é muito importância compreendermos a sala de aula como um espaço de pesquisa, de debate, de ensino e de aprendizagem, onde todos possam, espontaneamente, expressar-se sem terem seus comentários e posicionamentos ignorados.

Destarte, a relação entre os conceitos científicos sistematizados com os empíricos, fruto da experiência com o espaço vivido do alunado, facilita a construção e compreensão dos conceitos geográficos, resultando na construção de um novo e melhor elaborado conhecimento. 


\section{REFERÊNCIAS}

ALBUQUERQUE, Maria A. M. de. Século de prática de ensino de Geografia: permanências e mudanças. In: REGO, N.; CASTROGIOVANNI, A. C.; KAERCHER, N. A. (orgs.) Geografia: práticas para o ensino médio: volume 2. Porto Alegre: Penso, 2011. p. 13 - 32.

ALMEIDA, Rosângela D. A propósito da questão teórico-metodológica sobre o ensino de geografia. Revista Terra Livre, São Paulo: AGB, n. 8, p. 83-90. 1991. Disponível em: http://www.agb.org.br/publicacoes/index.php/terralivre/article/view/92. Acesso em: 23 jan. 2019.

ANDRADE, Manuel C. de. A Questão do Território. In: A questão do território no Brasil. 2. ed. São Paulo: HUCITEC, 2004. p. 13-19.

BOCK, A. M. B; FURTADO, O; TEIXEIRA, M. de L. T. Psicologia da Aprendizagem. In:__ Psicologias: uma introdução ao estudo de psicologia. 3. ed. São Paulo: Saraiva, 2002. p. 114-129.

BRASIL, Secretaria de Educação Fundamental. Parâmetros curriculares nacionais: geografia. Secretaria de Educação Fundamental. Brasília: MEC/ SEF, 1998. 156 p. Disponível em: http://portal.mec.gov.br/seb/arquivos/pdf/geografia.pdf. Acesso em: ago. 2018.

CALLAI, Helena C. A Geografia e a escola: muda a Geografia? Muda o ensino? Revista Terra Livre. São Paulo, n.16, p. 134-151. 2001. Disponível em: http://www.agb.org.br/publicacoes/index.php/terralivre/article/view/353. Acesso em: dez. 2018.

CARLOS, Ana F. A. Definir o Lugar? In: O lugar no/do mundo. São Paulo: Labur, 2007. p.16-20.

CAVALCANTI, Lana de S. Cotidiano, Mediação Pedagógica e Formação de Conceitos: uma Contribuição de Vygotsky ao Ensino De Geografia. Cad. Cedes, Campinas, v. 25, n. 66, p. 185-207, maio/ago. 2005. Disponível em: http://www.scielo.br/pdf/ccedes/v25n66/a04v2566.pdf. Acesso em: 17 jan. de 2019.

CAVALCANTI, Lana de S. A Geografia Escolar e a Cidade: ensaios sobre o ensino de Geografia para a vida urbana cotidiana. 3. ed. São Paulo: Papirus, 2010. (Coleção Magistério: formação e trabalho pedagógico).

CAVALCANTI, Lana. de S. Geografia, escola e construção de conhecimentos. 17 ed. Campinas-SP: Papirus, 1998.

CORRÊA, Roberto L. Região: um conceito complexo. In: Região e organização espacial. 2ed. São Paulo: Ática, 1987. p. 22-50.

DINIZ, Vanessa L.; COMPIANI, Maurício. O ensino de geografia e suas relações com a pedagogia crítica do lugar: contribuições para uma prática interdisciplinar. Rev. Geografia, Ensino \& Pesquisa, UFSM, v. 21, n. 1, p. 65-77, jan./abr. 2017. Disponível em: https://periodicos.ufsm.br/geografia/article/view/21789/pdf. Acesso em: 20 jul. 2019. 
FRANCO, Maria. A. R. S. Prática docente universitária e a construção coletiva de conhecimentos: possibilidades de transformações no processo ensino-aprendizagem. Cadernos de Pesquisa Universitária X, USP, São Paulo, set. 2009. Disponível em: http://www.prpg.usp.br/attachments/article/640/Caderno_10_PAE.pdf. Acesso em: 20 jul. 2019.

HALL, Stuart. A identidade cultural na pós-modernidade. 11 ed. Rio de Janeiro: DP\&A. 2006.

PONTUSCHKA, N. N.; PAGANELLI, T; CACETE, N. H. A Geografia como ciência e disciplina escolar. In: Para ensinar e aprender Geografia. São Paulo: Cortez, 2009. p. 35-104.

SAIKI, K.; GODOI, F. B. A prática de ensino e o estágio supervisionado. In: PASSINI, E. Y. (Org.). Prática de ensino de Geografia e estágio supervisionado. 2. ed. São Paulo: Contexto, 2010. p. 26-31.

SANTOS, Milton. Metamorfoses do espaço habitado: fundamentos teóricos e metodológicos da geografia. São Paulo: Hucitec, 1988. (versão digitalizada).

SATO, E. C. M.; FORNEL, S. R. Conhecimento do espaço escolar. In: PASSINI, E. Y. (Org.). Prática de ensino de geografia e estágio supervisionado. 2. ed. São Paulo: Contexto, 2010. p. 52-57.

SOARES, L. J. G. As políticas de EJA e as necessidades de aprendizagem dos jovens e adultos. In: RIBEIRO, V. M. (Org.). Educação de jovens e adultos: novos leitores, novas leituras. Campinas, SP: Ação Educativa, 2001. p. 201-224.

TICKS, Luciene K. (Re) Configuração Identitária de uma Professora de Lingua Inglesa por meio da pesquisa colaborativa. Linguagens \& Cidadania, v. 10, n.2, jul./dez., 2008. Disponível em: https://periodicos.ufsm.br/LeC/article/view/28272. Acesso em: 17 jun. 2019.

VASCONCELLOS, Celso. dos S. Conteúdo e forma da avaliação. In: Avaliação da Aprendizagem: práticas e mudanças - por uma práxis transformadora. 5. ed. São Paulo: Libertad, 2003. p. 91-132. (Coleção Cadernos Pedagógicos do Libertad, v.6). 